\title{
Mating strategies to maximize genetic merit in dairy cattle herds
}

\author{
T. Johnson, ${ }^{*}$ K. Eketone, ${ }^{*}$ L. McNaughton, ${ }^{*}$ K. Tiplady, ${ }^{*}$ J. Voogt, $†$ R. Sherlock, ${ }^{*}$ G. Anderson, ${ }^{*}$ M. Keehan, ${ }^{*}$ \\ S. R. Davis, ${ }^{*}$ R. J. Spelman, ${ }^{*}$ D. Chin, $\ddagger$ and C. Couldrey* \\ *Research and Development, \\ †Emerging Markets and Innovation, and \\ ‡Transformation Office, Livestock Improvement Corporation, Hamilton, New Zealand 3286
}

\section{ABSTRACT}

The genetic merit of a herd is a key determinant in productivity for dairy farmers. However, making breeding decisions to maximize the rate of genetic gain can be complex because there is no certainty about which cows will become pregnant with a heifer calf. In this study, breeding worth $(\mathrm{BrW})$ was used as a measure of genetic merit, and several mating strategies were evaluated. These strategies included randomly mating whole herds to the entire bull team, excluding low-ranked cows from producing replacement heifers, and nominating high-ranked cows to the most highly ranked bulls. Simulations were undertaken using 4 bull teams generated from bulls currently marketed in New Zealand and a selection of New Zealand dairy herds. Average replacement heifer $\mathrm{BrW}$ was calculated for 1,000 iterations of each combination of mating strategy, herd, and bull team (scenario). Variation in resulting average replacement heifer BrW within scenarios was due to random sampling of which cows became pregnant with a heifer calf. Relative to mating the whole herd to an entire bull team, excluding the lowest ranked cows from producing replacements resulted in the greatest increase in average replacement heifer BrW across all herds and bull teams, with a gain of approximately 0.4 $\mathrm{BrW}$ point for each $1 \%$ of cows excluded. Nominating top-ranking cows to the highest ranking bulls in the team had little effect $(0.06-0.13 \mathrm{BrW}$ increase for each $1 \%$ of top cows nominated) in improving BrW of replacement heifers. The number of top bulls nominated had a variable effect depending on the BrW spread of the entire bull team. Although excluding cows with the lowest $\mathrm{BrW}$ from producing replacement heifers is most effective for improving $\mathrm{BrW}$, it is important to ensure that the number of heifers born is sufficient to replace cows leaving the herd. It is likely that optimal strategies for improving $\mathrm{BrW}$ will vary from farm to farm

Received July 20, 2017.

Accepted January 1, 2018.

${ }^{1}$ Corresponding author: Christine.couldrey@lic.co.nz depending not only on the BrW structure of the herd, the bull team available, and the reproduction success on farm but also on farm management practices. This simulation study provides expected outcomes from a variety of mating strategies to allow informed decision making on farm.

Key words: dairy cattle, breeding worth, genetic improvement

\section{INTRODUCTION}

Dairy farming contributes approximately 37\% of the total value that New Zealand earns from export (DairyNZ, 2014b). Although the returns for milk adjusted for inflation have declined in the last $20 \mathrm{yr}$, selective breeding for genetic improvement has allowed economic efficiency to be maintained on New Zealand dairy farms (Harris et al., 2007). Given the current volatility in global dairy prices and the recent decline in numbers of dairy cattle in New Zealand (LIC and DairyNZ, 2016), genetic improvement remains a vital part of dairy farming. The success of selective breeding for genetic improvement in New Zealand dairy cattle is largely due to the national breeding objective "to breed dairy cows that are able to efficiently convert feed into profit." To rank cows and bulls according to their ability to meet the national breeding objective, an economic index known as breeding worth (BrW; Harris et al., 2007) has been developed. This across breeds genetic evaluation makes adjustments for the fact that multiple breeds of dairy cattle are milked in New Zealand (19.8\% Holstein Friesian, 7.3\% Jersey, 70.6\% Holstein Friesian $\times$ Jersey, and $2.3 \%$ other breeds; Livestock Improvement Corporation internal database, Hamilton, New Zealand) and that the vast majority of herds contain genetics from multiple breeds $(<2 \%$ of herds contain only a single breed; Livestock Improvement Corporation internal database). The $\mathrm{BrW}$ index is calculated by combining breeding values (genetic merit for individual traits) with estimated economic values (per dollar unit increase) of the trait to a New Zealand dairy farmer. The traits used in the $\mathrm{BrW}$ index 
are milk fat, protein, milk volume, live weight, fertility, SCC, BCS, and residual survival (DairyNZ, 2014a). Breeding worth is expressed as dollars of net farm income per $5 \mathrm{t}$ of $\mathrm{DM}$ relative to a genetic base cow (currently the average of cows born in 2005; DairyNZ, 2014a). Currently, 1 genetic standard deviation equals 80 points. The $\mathrm{BrW}$ index is therefore able to compare animals across breeds. This allows farmers to easily rank animals in the herd for their genetic ability to breed replacements even if the herd consists of multiple breeds. Given that the BrW index is specifically designed to breed for genetic improvement in accordance with the national breeding objective, it does not aim to capture heterosis and currently does not capture dominance effects. In New Zealand, both heterosis and all other nonadditive effects are captured as production worth (DairyNZ, 2015).

Culling of cows based on their performance is one strategy for improving production efficiency. However, in terms of herd improvement, it is essential that young heifers entering the herd are genetically superior to the cows they are replacing. Although this may seem intuitive, making breeding decisions to maximize the genetic merit of the herd can be complex. Some of this complexity stems from the fact that it is not possible to know which cows will come into heat and be submitted for AI or which will become pregnant with a female calf. This complexity is of particular importance in the seasonal dairy farming systems common in New Zealand, where a calving interval of close to 365 d needs to be maintained (Holmes et al., 2002). In these seasonal systems, only cows becoming pregnant in the short AI period (typically 3-6 wk) are able to generate herd replacements.

Despite the complexities, there is much interest in maximizing genetic merit within dairy herds. A considerable number of studies have produced models to maximize genetic gain; however, these studies have either been undertaken in the context of bull breeding to produce the best bulls (Börner et al., 2012; ReinerBenaim et al., 2017) or modeled the effectiveness of new reproductive technologies (e.g., embryo transfer) and the use of genomics (Calus et al., 2015; Thomasen et al., 2016). Currently, the use of new reproductive technologies is still very much in the minority in commercial dairy farms in New Zealand $(<0.2 \%$ of calves born in New Zealand). Similarly, the use of genomics for female selection is very limited in New Zealand, largely due to the challenges faced in undertaking genomic prediction in a largely crossbred population. Given these practicalities, there is currently a lack of scientific data around different mating strategies that farmers can easily use on farm to maximize the genetic gain on offer from breeding companies while also taking into account their individual farming systems and breeding goals. Here we used BrW data from New Zealand herds and current bulls to simulate the effects of different mating strategies on replacement heifer $\mathrm{BrW}$ and ultimately identify the most efficient and maximal rate at which $\mathrm{BrW}$ may be improved. There are 2 distinct opportunities during which the average $\mathrm{BrW}$ of replacement heifers entering the herd may be influenced: (1) at mating to generate the replacements and (2) before the heifers enter the herd, when the best of those calves generated can be selected (assuming that sufficient calves have been generated by the mating strategy at the earlier opportunity). The data presented here examine the decisions made only at the time of mating, as this is the more complex of the two.

\section{MATERIALS AND METHODS}

\section{Data}

Herd Selection. Herds were selected from all New Zealand recorded herds with at least 100 cows $(10,755$ herds). Individual animal $\mathrm{BrW}$ were used to calculate the average $\mathrm{BrW}$ and standard deviation of $\mathrm{BrW}$ for each herd. The relationship between average herd BrW and the standard deviation of herd BrW, as well as average herd $\mathrm{BrW}$ relative to herd size, is shown in Figure 1. A subset of herds was selected as representative herds to be used in simulation studies. The first selection criteria were based on the average herd size in New Zealand being approximately 400 cows (LIC and DairyNZ, 2016); herds of 300 to 500 cows were therefore selected. Within this herd size, the distributions of average herd $\mathrm{BrW}$ and the standard deviation of herd $\mathrm{BrW}$ were used to define 5 groups of herds (Table 1): high BrW with low standard deviation $(\mathrm{n}=18)$, average $\mathrm{BrW}$ with low standard deviation $(\mathrm{n}=16)$, average $\mathrm{BrW}$ with high standard deviation $(\mathrm{n}=4)$, low $\mathrm{BrW}$ with low standard deviation $(\mathrm{n}=7)$, or low $\mathrm{BrW}$ with high standard deviation $(\mathrm{n}=7)$. No herds with high $\mathrm{BrW}$ and high standard deviation were observed.

Bull Team Selection. Bull teams were generated from the current ranking of active sires (RAS) list March 28, 2017 (DairyNZ, 2017), based on their BrW and rank overall for a mixed-breed team or within breed for a breed-specific team. Reliability of BrW for each of the bulls was greater than $79 \%$. Figure 2 shows the variation in the distribution of $\mathrm{BrW}$ for the 10 bulls in each of the 4 bull teams used. The mixed-breed team made up of the top 10 bulls on the RAS list (regardless of breed) had a very narrow spread of 13 BrW points with one exception, where the top bull had a BrW that was 42 points higher than that of the second highest bull. The team consisting of the top 10 Jersey bulls had 

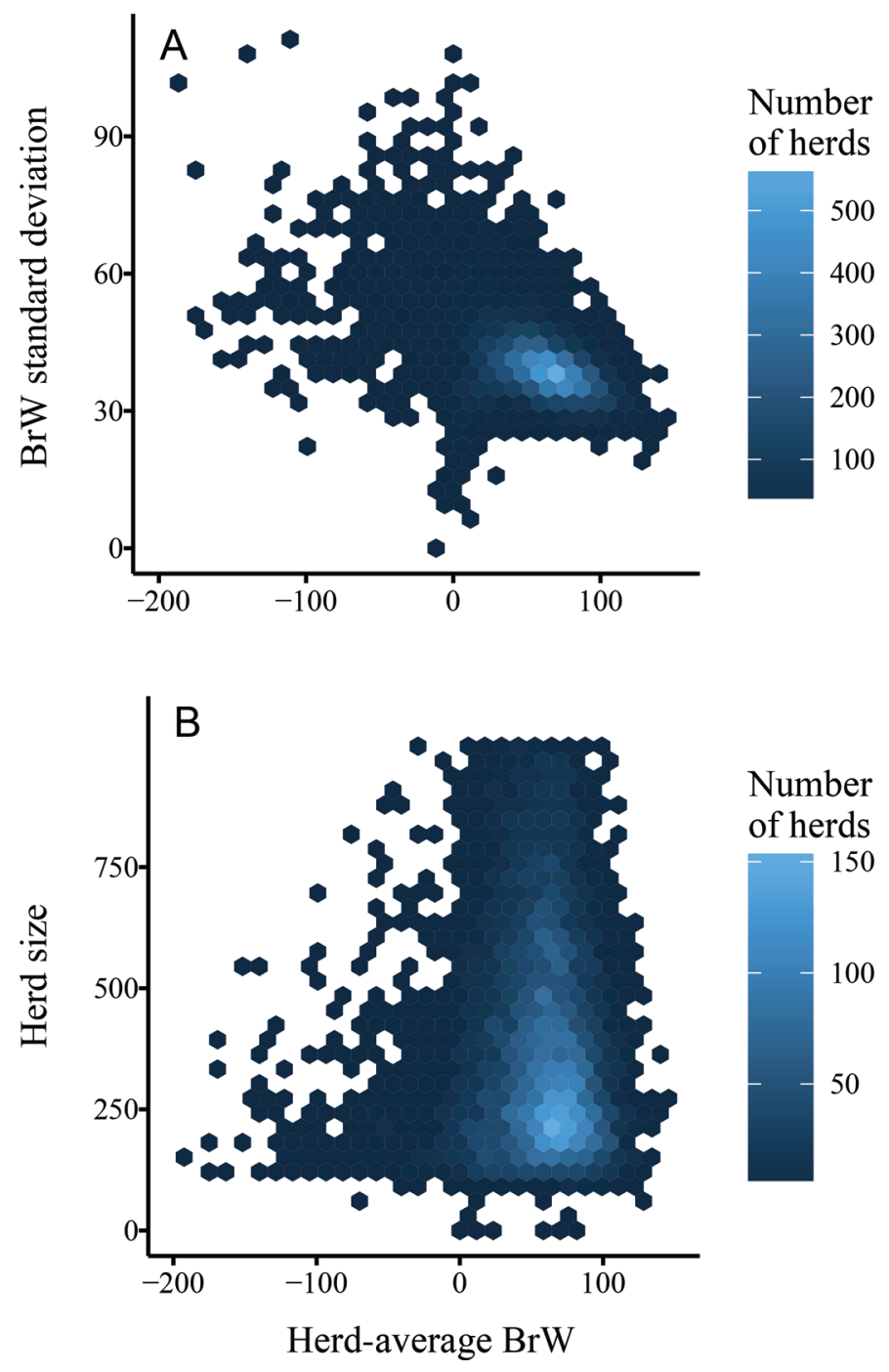

Number of herds

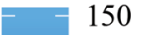

Figure 1. New Zealand dairy cattle herd size and distribution of breeding worth $(\mathrm{BrW})$. (A) Distribution of average and SD of herd $\mathrm{BrW}$. (B) Average herd BrW and herd size for herds with fewer than 1,000 cows. Color of point represents number of herds. Color version available online.

a moderate $\mathrm{BrW}$ range of 22 points, whereas the $\mathrm{BrW}$ spread of the KiwiCross bull team was higher than that of both the Jersey and the mixed-breed teams at 29 $\mathrm{BrW}$ points. The Holstein Friesian team had the largest spread of BrW with a range of 36 points (excluding

Table 1. Classification ranges for herd selection based on average and SD of herd breeding worth (BrW)

\begin{tabular}{lccc}
\hline & \multicolumn{3}{c}{ Classification } \\
\cline { 2 - 4 } Item & High & Average & Low \\
\hline Herd BrW average & $100-110$ & $55-65$ & $10-20$ \\
Herd BrW SD & $55-65$ & - & $22-32$ \\
\hline
\end{tabular}

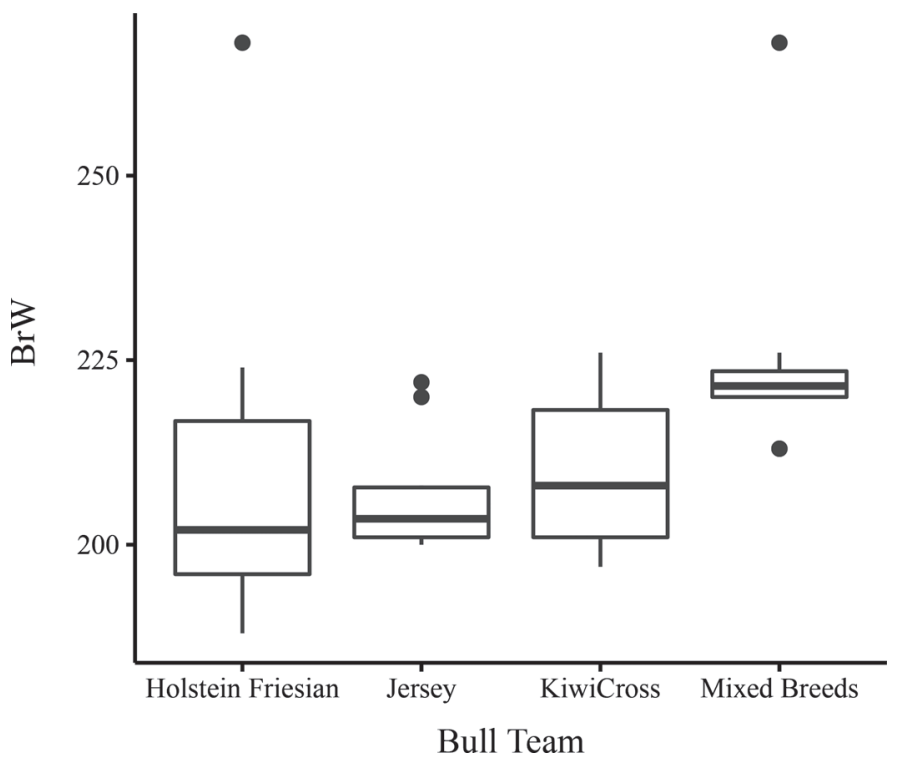

Figure 2. Distribution of breeding worth $(\mathrm{BrW})$ for each of the 4 bull teams used in simulations. Each team included 10 bulls selected from the top of the New Zealand ranking of active sires list March 28, 2017 (DairyNZ, 2017). The mixed breed team included bulls from all 3 breeds, whereas the Holstein Friesian, Jersey, and KiwiCross teams consisted of bulls from a single breed only. The upper, middle, and lower lines in each plot define the upper quartile, median, and lower quartile, respectively. The 95th percentile and outliers are indicated by vertical lines and dots, respectively.

the highest BrW bull), with the highest ranked bull having a BrW that was 44 points higher than that of the second highest bull.

Usage of AI in New Zealand. Using the 8,510, 8,602 , and 8,329 herds recorded with at least 100 inseminations, the average length of AI in New Zealand seasonal herds (inseminated in spring) for 2013, 2014, and 2015 was calculated to be 40.2, 44.6, and $45.1 \mathrm{~d}$, respectively. Analyzing the distribution of length of AI (Supplemental Figure S1, https://doi.org/10.3168/jds .2017-13538) illustrates that the common AI lengths in New Zealand are 28, 35, and $42 \mathrm{~d}$, with a small proportion of farms undertaking AI for as few as $21 \mathrm{~d}$. Based on the distribution of AI length in New Zealand farms over the past $3 \mathrm{yr}$, we simulated AI lengths of 21 , 28, 35, and $42 \mathrm{~d}$ in our model. Although some farms undertake AI for longer periods, on most New Zealand dairy farms it is not practical or desirable for replacement calves to be kept after the first $6 \mathrm{wk}$ of calving.

Average pregnancy rates after the first 6 wk of mating and AI were obtained from New Zealand Dairy statistics (LIC and DairyNZ, 2016). In-calf rates at different stages of mating were calculated from pregnancy data in the spring of the 2016 season. Seasonal herds of greater than 100 cows, for which age of fetus was reported in at least $80 \%$ of cows during pregnancy 
Table 2. Pregnancy rate parameters and levels of breeding worth (BrW) used in mating simulations

\begin{tabular}{ll}
\hline Parameter & Levels \\
\hline $\begin{array}{l}\text { Percentage of lowest BrW cows excluded from producing replacements } \\
\text { Percentage of highest BrW cows mated to nominated bulls }\end{array}$ & $0,5,10,15$, and 20 \\
Number of top bulls nominated & $0,5,10,15$, and 20 \\
Pregnancy rate after AI & $4,1,3$, and 5 \\
BrW spread of bull team & Top 10 bulls regardless of breed (mixed breed), top \\
& 10 Holstein Friesian bulls, top 10 Jersey bulls, top 10 \\
& KiwiCross bulls ${ }^{3}$ \\
\hline${ }^{1} 0$ indicates that the full bull team was used (no cows are nominated). & \\
${ }^{2}$ These values represent the combination of length of AI, submission rate, and conception rate based on New Zealand national average pregnancy \\
rate after $3,4,5$, and 6 wk of mating.
\end{tabular}

testing, were selected (3,994 herds). The percentage of cows pregnant on each day from the start of mating was calculated for each herd using aged pregnancies and the total number of cows present in the herd at the start of mating. These pregnancy rates were then used to calculate nationwide averages (Supplemental Figure S2, https://doi.org/10.3168/jds.2017-13538). From this, the average percentage of pregnant animals after $21,28,35$, and $42 \mathrm{~d}$ of mating was calculated to be $46,55,63$, and $68 \%$, respectively.

\section{Simulation Parameters}

Matings were simulated for each combination of parameters listed in Table 2 for each of the herds selected. A mating strategy was defined as a single combination of (1) percentage of cows excluded from producing replacement heifers, (2) percentage of cows nominated to top bulls, (3) number of top bulls used for nomination, and (4) pregnancy rate after AI period.

Individual cow BrW for each herd were used to identify the top cows for nominated mating to the top bulls. Similarly, the bottom cows were identified based on $\mathrm{BrW}$ and were ineligible for generating replacement heifers. The remainder of the cows were randomly mated to bulls in the appropriate team to generate pregnancy rates of $46,55,63$, and $68 \%$ to mimic the effect of $3,4,5$, and 6 wk of AI, respectively (based on AI length and pregnancy rates observed in New Zealand farms). The average percentage of heifer calves was set at $49 \%$, and, based on data from previous studies, it was assumed that $93 \%$ of calves would be born live and survive beyond 48 h (Cropp, 2003; Pryce et al., 2006). Within these parameters, sex and survival to $48 \mathrm{~h}$ after birth were assigned randomly. Parent-average BrW was used to determine $\mathrm{BrW}$ of the resulting heifer calves.

For each herd, each combination of parameters was simulated 1,000 times, resulting in a total of 54,000,000 simulated herd matings. For each simulated mating, the number of heifers produced as potential replace- ment animals and the average BrW of the replacement group were determined.

\section{Statistical Analysis}

To estimate the effect of different mating strategies on the average BrW of replacement heifers generated, linear models were fitted in $\mathrm{R}$ ( $\mathrm{R}$ CoreTeam, 2014). Different mating strategies were represented by including covariates in the model for the percentage of cows excluded from producing replacement heifers, the percentage of cows mated to top bulls, and the number of top bulls used for nominated matings. These linear models were fitted for each of the bull teams independently.

\section{RESULTS}

\section{Herd Selection, Bull Team BrW, Length of Al, and Average Pregnancy Rates in New Zealand}

A total of 52 herds were selected to represent a range of herd-average BrW and standard deviations in the average herd size in New Zealand (300-500 cows). The 4 bull teams generated from the RAS list varied not only in average BrW but also in spread of $\mathrm{BrW}$ within the bull team (Figure 2). In the 2016 spring mating season, the average percentage of pregnant animals after 21 , 28,35 , and 42 d of mating was calculated to be 46,55 , 63 , and $68 \%$, respectively. These calculated parameters were subsequently used in the simulation.

\section{Simulation Results}

Figure 3 shows the average BrW for potential replacement heifers, with 1,000 iterations simulated for each strategy, for a single herd (mean $\mathrm{BrW}=58.7$, $\mathrm{SD}=55.5$ ) and a single bull team (KiwiCross). The variation in mean replacement heifer BrW across the 1,000 iterations was similar for each strategy tested. 


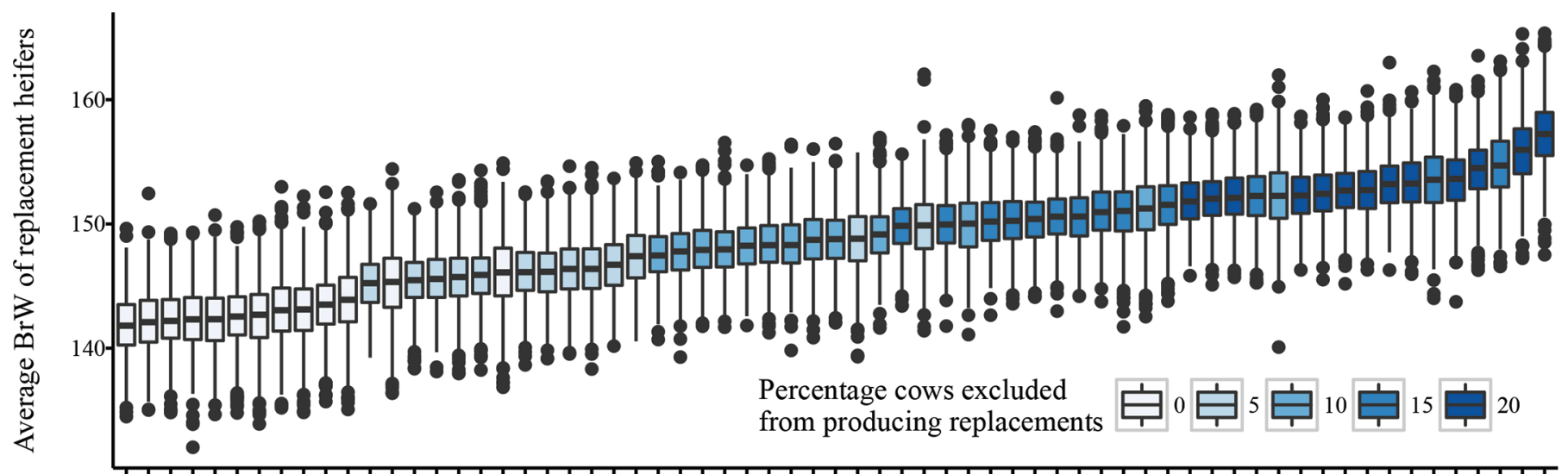

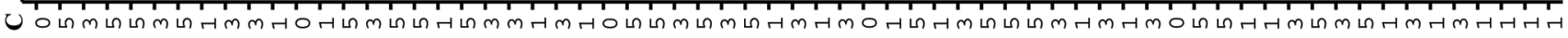
ص 의 《 00000000000 n

Mating strategy

Figure 3. Simulation results for a single herd in which average herd breeding worth (BrW) was average (55-65) and SD of herd BrW was high (55-65) for the KiwiCross bull team. Average BrW of simulated replacement heifers is plotted for 1,000 iterations of each mating strategy. (A) Percentage of low BrW cows excluded from generating replacement heifers. (B) Percentage of high BrW cows nominated to top sires. (C) Number of top sires used for nomination. The upper, middle, and lower lines in each plot define the upper quartile, median, and lower quartiles, respectively. The 95th percentile and outliers are indicated by vertical lines and dots, respectively. Color version available online.

This variation was approximately $15 \mathrm{BrW}$ points between iterations that produced the highest and lowest $\mathrm{BrW}$ offspring within each strategy tested. When other herds and bull teams were analyzed, the level of varia-

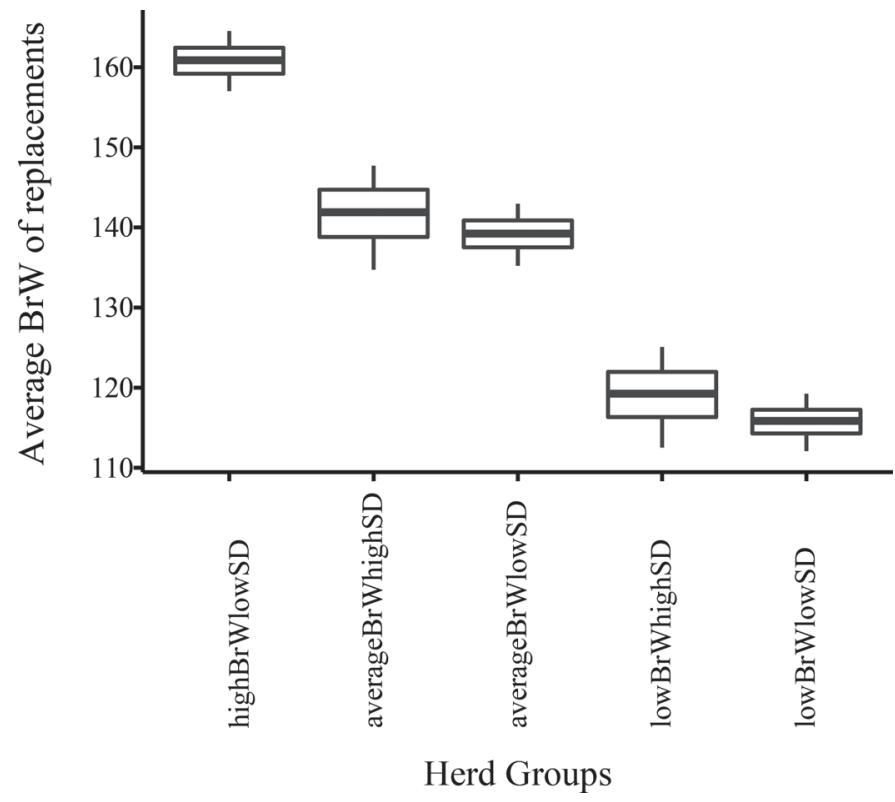

Figure 4. Average breeding worth $(\mathrm{BrW})$ of replacement heifers across all strategies. Average $\mathrm{BrW}$ of replacements were generated across iterations in all herds and are shown by herd group. The upper, middle, and lower lines in each plot define the upper quartile, median, and lower quartile, respectively. The 95th percentile is represented with vertical lines. tion in average replacement heifer $\mathrm{BrW}$ from iteration to iteration did show some variation across different herds and bull teams and was dependent on the BrW spread of the herd and, to a lesser extent, the bull team being analyzed (further examples of different herds and bull teams are provided in Supplemental Figure S3, https://doi.org/10.3168/jds.2017-13538). For the herd and bull team (KiwiCross) shown in Figure 3, the strategy performing least well (all cows mated randomly to the full bull team) on average generated a cohort of replacement heifers with a BrW of 141.9. In contrast, the highest performing strategy on average produced a cohort of replacements with a mean BrW of 157.2. The difference in average BrW between the poorest and best performing mating strategies across all simulated matings was again largely dependent on the distribution of $\mathrm{BrW}$ in the herd and, to a lesser extent, the bull team used. These differences in range of mean $\mathrm{BrW}$ for all strategies across different groups of herds using a single bull team (KiwiCross) are summarized in Figure 4. Herds with a high standard deviation in $\mathrm{BrW}$ across the cows had a wider range of outcomes across the strategies tested and allowed greater $\mathrm{BrW}$ gains to be achieved (similar results were obtained from all bull teams; data not shown).

To better understand the effects of different bull teams and the effect of different mating strategies across herds with differing BrW distributions, we undertook a more detailed examination of the differences in average $\mathrm{BrW}$ of replacement heifers generated from different 
mating strategies. Figure 5 provides a summary of the average replacement $\mathrm{BrW}$ generated across multiple herds for each strategy when using the KiwiCross bull team (more in-depth data for all bull teams are provided in Supplemental Figure S4, https://doi.org/10 .3168/jds.2017-13538). Across all herds and bull teams, strategies in which none of the bottom cows were excluded from producing replacements tended to result in replacement heifers having a lower average $\mathrm{BrW}$ than strategies that excluded the lowest BrW cows producing replacement heifers. The greater the percentage of cows excluded, the higher the average BrW of replacements. Less obvious were the differences caused by nominating top cows to top bulls (with higher percentages of nominated cows resulting in replacements with higher $\mathrm{BrW}$ ) and the number of bulls used in nomination (the smaller the number, the higher the resulting average offspring $\mathrm{BrW}$ ). These trends were most obvious in herds with a large spread in BrW (i.e., herds with high standard deviation; Figure 5) and in the KiwiCross and
Jersey bull teams (Figure 5; Supplemental Figure S4), which did not include a bull with an exceptionally high BrW. For these herds with high standard deviation or with Jersey or KiwiCross combinations, all strategies with no cows excluded from producing replacement heifers ranked lower than all those with the bottom $5 \%$ excluded. In turn, those strategies with the bottom $5 \%$ of cows excluded from producing replacement heifers were lower than all those with the lowest $10 \%$ of cows excluded and so on. The other components of the strategies were not separated as clearly. For herds that were made up of cows with a narrower range in BrW (i.e., herds with low standard deviation; Figure 5) or using bull teams with a single bull of very high BrW (Supplemental Figure S4), the separation of strategies was less clear.

Linear models were fitted to assess the contribution of each component of our simulated matings for each bull team separately. Adjusting for the average $\mathrm{BrW}$ and standard deviation of $\mathrm{BrW}$ in each herd allowed

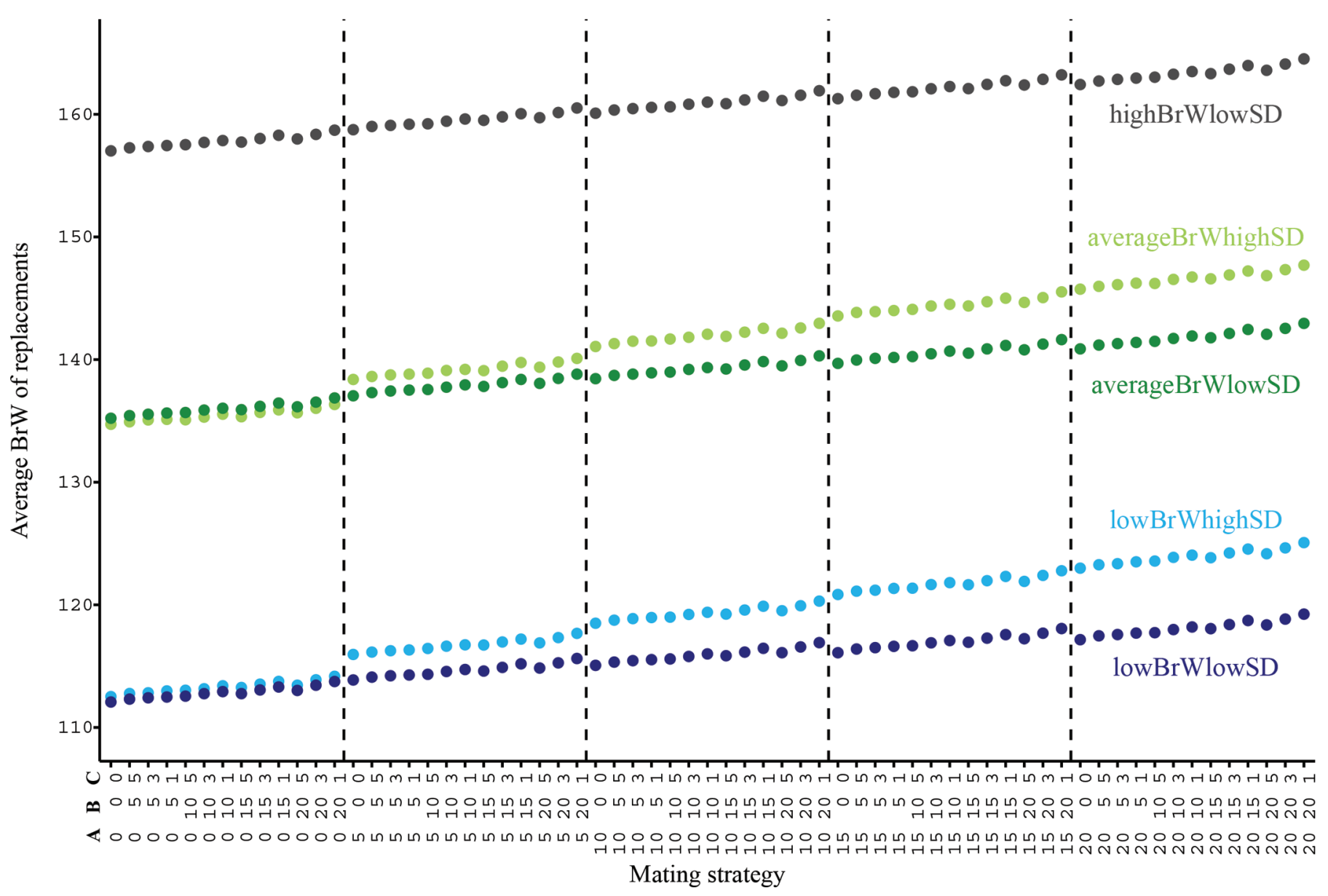

Figure 5. Average breeding worth $(\mathrm{BrW})$ of replacement heifers across all strategies using the KiwiCross bull team. (A) Percentage of low BrW cows excluded from generating replacement heifers. (B) Percentage of high BrW cows nominated to top sires. (C) Number of top sires used for nomination. Standard deviations have not been plotted due to their small size (0.7-1.8). Color version available online. 
Table 3. Effect size and statistical significance of breeding worth (BrW) and top bull parameters simulated across all herds and bull teams ${ }^{1}$

\begin{tabular}{|c|c|c|c|c|}
\hline \multirow[b]{2}{*}{ Parameter } & \multicolumn{4}{|c|}{ Bull team } \\
\hline & $\begin{array}{l}\text { Mixed } \\
\text { breed }\end{array}$ & Jersey & KiwiCross & $\begin{array}{l}\text { Holstein } \\
\text { Friesian }\end{array}$ \\
\hline Percentage of high BrW cows nominated to top bulls & $0.07^{* * *}$ & $0.07^{* * *}$ & $0.06^{* * *}$ & $0.13^{* * *}$ \\
\hline Number of top bulls used in nomination & $-0.31^{* * *}$ & $-0.14^{* * *}$ & $-0.06^{*}$ & $-0.39 * * *$ \\
\hline
\end{tabular}

${ }^{1}$ For each percentage of cows excluded or nominated, the effect size represents the gain or loss in BrW. Similarly, for each additional bull nominated, the effect size represents the gain or loss in BrW.

${ }^{*} P<0.05$. ${ }^{* * *} P<2 \mathrm{E}-16$.

for the effect of the 3 individual components of each strategy to be determined. This also identified that the percentage of lowest $\mathrm{BrW}$ cows excluded from producing replacement heifers had the greatest effect regardless of bull team used (Table 3). In contrast, the effects of the percentage of top cows nominated to top bulls and the number of bulls nominated were dependent on the BrW spread of the bull team used and whether a bull of very high BrW was present in the team.

Although the effect of differing length of AI period does not affect the average $\mathrm{BrW}$ generated across the strategies (data not shown), it does affect the number of heifer calves that are generated. Figure 6 illustrates the percentage of herd replacements (animals from which herd replacements can be selected) generated and born alive when varying percentages of the cows (with the lowest $\mathrm{BrW}$ ) are excluded from producing replacements. The horizontal line at $25 \%$ indicates a desirable number of replacement heifers born. With shorter AI periods, fewer cows are pregnant and hence fewer heifer calves are born alive. Figure 6 also shows the considerable amount of variation in the percentage of herd replacements generated across the 1,000 simulated matings for each strategy in this herd.

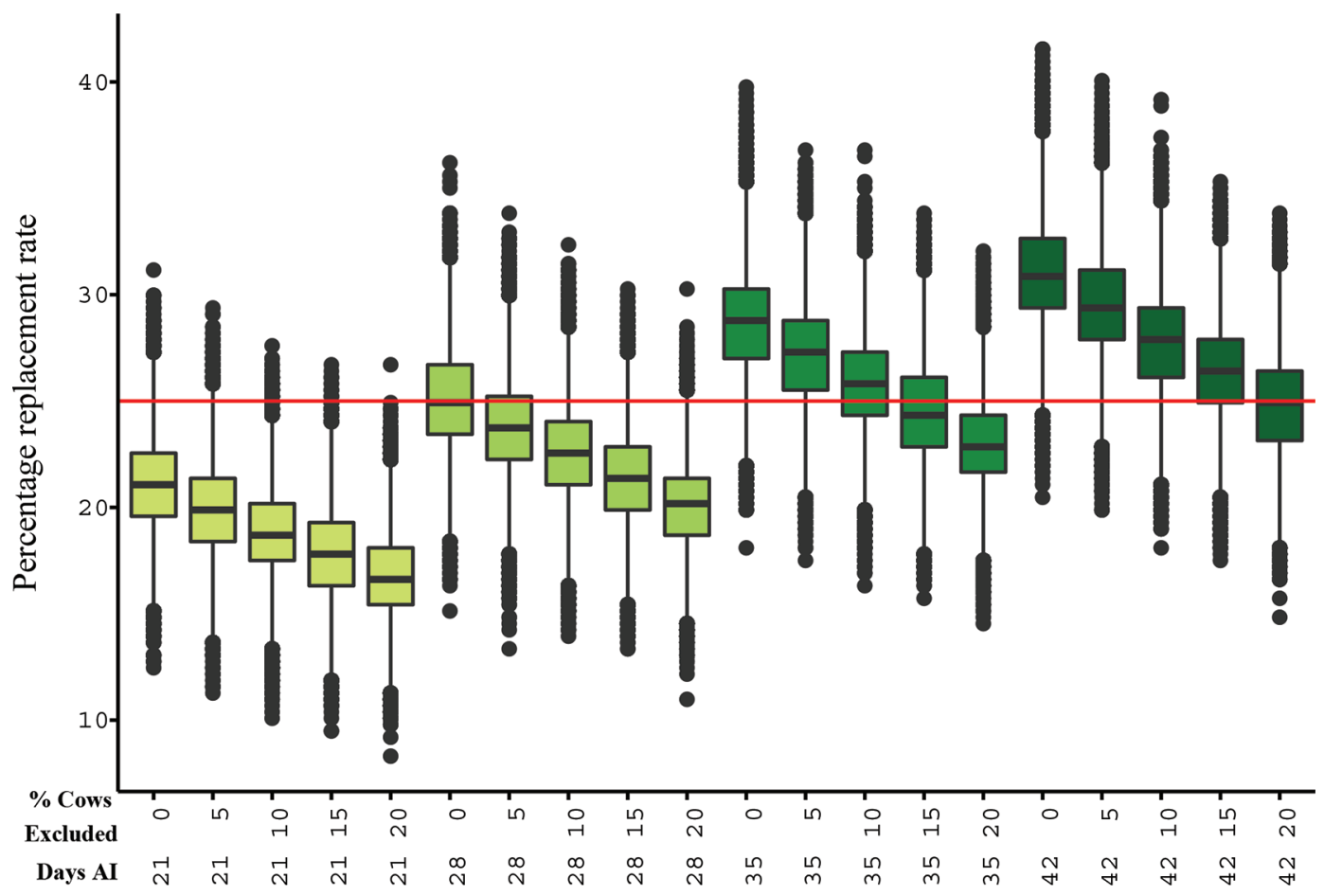

Figure 6. Percentage of replacement rate generated from AI periods of different lengths and excluding different percentages of the lowest breeding worth cows from producing replacements. All iterations of all herds are illustrated. The upper, middle, and lower lines in each plot define the upper quartile, median, and lower quartile, respectively. The 95th percentile and outliers are indicated by vertical lines and dots, respectively. Color version available online. 


\section{DISCUSSION}

Genetic gain is a key component of increasing productivity for New Zealand dairy farmers. Although some potential to improve herd genetics through the purchase of cows with superior genetics exists, for practical and financial reasons the scope of this is limited. Much of the on-farm genetic gain for any given herd needs to be accomplished through the breeding of replacement heifers with genetic merit superior to that of cows currently in the herd. Intuitively, many farmers believe that mating their very best cows to only the very top bulls will maximize the rate of genetic gain in their herd. In this study, we used BrW as a measure of genetic merit. However, the results are applicable to any of the individual components that contribute to BrW.

Simulating random matings of cows in herds (selected to represent a cross-section of New Zealand dairy herds) with 4 different bull teams generated from bulls currently marketed in New Zealand allowed assessment of different mating strategies based on the resulting average $\mathrm{BrW}$ of replacement heifers generated. Being able to simulate this number of matings for each combination of herd, bull team, and strategy clearly illustrates the potential variation in average $\mathrm{BrW}$ of replacement heifers that may be generated on any given year from a single mating strategy and bull team. Although it is necessary to consider average outcomes across multiple herds, the spread of variation possible by random chance (i.e., which cows conceive a heifer calf in the appropriate time frame) is an important factor to consider when analyzing these data and when providing mating plan suggestions to farmers interested in improving genetic gain in their herds. It should be noted that the spread of variation in our data is likely to somewhat underrepresent the variation that may be observed in practice due to 2 separate factors. First, the reliability of $\mathrm{BrW}$ calculations is less than $100 \%$ (bulls were all $>79 \%$, but cow $\mathrm{BrW}$ reliabilities typically range between 45 and $60 \%$ depending on the number of recorded offspring and lactations). Second, in this simulation, we did not include Mendelian sampling as a separate factor; rather, its average was included by using parent average to calculate offspring BrW. These additional sources of variation apply across all herds and bull teams.

Given that the BrW of bull teams was higher than that of the herds, the simplest strategy of mating all cows to the full bull team always results in a replacement cohort with a higher average $\mathrm{BrW}$ than the current herd average. However, when 1,000 iterations of matings were considered, on average this strategy performed the most poorly in all herd-bull team com- binations. In contrast, on average, excluding the bottom $20 \%$ of cows from producing a replacement and simultaneously nominating the top $20 \%$ of cows to the single top bull produced, on average, the highest $\mathrm{BrW}$ offspring across all herd types and bull teams.

By simulating all possible combinations of excluding cows from producing replacements, nominating top cows to top bulls, and the number of top bulls nominated, we identified that the single biggest factor in improving $\mathrm{BrW}$ comes from excluding the lowest $\mathrm{BrW}$ cows from producing replacement heifers, similar to the findings of Ettema et al. (2017). For each $10 \%$ of the bottom cows (based on BrW) excluded from generating a replacement, the average $\mathrm{BrW}$ of replacements generated increased by 3.8 to $4.0 \mathrm{BrW}$ regardless of herd structure or bull team used. In contrast, the effect of mating the top $10 \%$ (based on BrW) to the top bulls typically resulted in the average $\mathrm{BrW}$ of replacements increasing by less than 1 . The most variable effect on herd $\mathrm{BrW}$ was from the number of top bulls used for top cow nomination. Bull teams that contained a single bull with an extraordinarily high $\mathrm{BrW}$ relative to the remainder of the team were able to affect the average $\mathrm{BrW}$ of the replacements generated. However, the occurrence of teams with this distribution of $\mathrm{BrW}$ is uncommon in New Zealand. A BrW difference between the top 2 bulls as large as that observed in the Holstein Friesian and KiwiCross bull teams has occurred on only 5 occasions across all bull teams since 1996 (Livestock Improvement Corporation, Hamilton, New Zealand, unpublished data).

In reality, both nomination of top $\mathrm{BrW}$ cows to top bulls and the number of top bulls nominated will contribute less to increasing the $\mathrm{BrW}$ of replacement heifers than reported here. The overestimation of average replacement heifer $\mathrm{BrW}$ in the simulations reported here results from the random mating of all cows (not selected for nomination) to all bulls in the team equally. In New Zealand, on-farm semen usage is not completely random due to the extensive use of liquid semen $(\sim 71 \%$ of inseminations in the spring season in 2016; LIC and DairyNZ, 2016). With bull teams being collected for fresh semen delivery, top bulls are preferentially used to produce more straws and so contribute disproportionately more to the number of heifer calves generated than their lower BrW teammates. On farm (compared with the simulations presented here), a smaller increase in $\mathrm{BrW}$ will be realized when cows are nominated to top bulls (which are also present in the bull team).

Given that the biggest advance in replacement heifer $\mathrm{BrW}$ can be achieved by excluding low BrW cows from producing replacements, it may be tempting to overlook potential challenges faced in the implementation of strategies that involve not keeping replacements from 
low BrW cows. The first of these potential challenges is the requirement for being absolutely certain on parentage of calves. This necessitates DNA parentage testing at an early age, ensuring that cows excluded from producing replacements are calved separately, or mating low BrW cows to sires selected to produce calves that are easily identified by coat color (e.g., use of a Hereford sire to generate calves with white faces, which can then be excluded). A second challenge, equally as important but potentially more difficult to overcome, is the need to generate a sufficiently large number of replacement heifers to ensure a desirable herd size and age structure. The optimal replacement rate, based on trade-offs between incorporation of improved genetics and lifetime efficiency of cows in New Zealand, has been reported to be $18 \%$ (Holmes et al., 2010). Generating a sufficient number of replacement heifers when excluding low BrW cows from producing replacements is absolutely dependent on both the reproductive performance of the individual herds and the length of AI. The red line in Figure 6 shows an approximate level of replacement heifers that need to be born alive to result in an $18 \%$ replacement rate of 2-yr-old heifers entering the herd (assuming 7\% loss based on DairyNZ statistics; DairyNZ, 2014b). This figure clearly illustrates the challenges faced in generating sufficient heifers in herds with national average pregnancy rates. Even if no cows are excluded from generating replacements, with a very short AI period (i.e., $3 \mathrm{wk}$ ) there are seldom enough replacement heifers generated in herds when reproductive performance is the same as the national average. In these herds, it is not until the AI period is extended to at least 5 wk that there is an opportunity to exclude the bottom BrW cows from producing a replacement heifer but still be able to generate sufficient replacement heifers. Herds with higher reproductive performance can generate sufficient replacement heifers with fewer days of AI. Maximizing the rate of genetic gain through the exclusion of low BrW cows absolutely requires good reproductive performance and 6 wk of AI. In cases in which high value is placed on genetic gain, the number of high BrW replacement heifers generated may be increased by also undertaking AI on heifers that are to enter the milking herd. However, given the small percentage of animals that this represents, it is not a simple solution to offset the consequences of a short AI length or poor reproductive performance. Instead, this should be viewed as a supplemental approach. A strategy for maximizing genetic merit should combine improving reproduction rates and undertaking $6 \mathrm{wk}$ of AI (or longer if calves after the first 6 wk of calving are raised as replacements) with AI of yearling heifers in an attempt to produce surplus calves to allow further selection of the highest genetic merit calves once they are born.

Although nominating top BrW cows to the very top $\mathrm{BrW}$ bulls contributes to genetic gain more than mating all cows to the entire bull team, it is not without its challenges and is unlikely to be an optimal long-term strategy. The first challenge, particularly if $20 \%$ of the herd were to be mated to a single nominated bull, is the potential increase in population levels of inbreeding. A second challenge, nominating large numbers of cows to a single bull, can be limited by the availability of semen. This is particularly relevant when there is a widespread high demand for a particular bull. A further challenge is whether the bull's individual traits (measured by breeding values) are widely desirable to individual farmers (e.g., temperament, live weight).

The simulation of mating strategies presented here has focused on $\mathrm{BrW}$ as a measure of genetic merit; however, the same model can be used to assess any trait for any heritable trait where breeding values, indexes, or evaluations have been generated. The model presented here is applicable to seasonal dairy farming worldwide. We view this system as a useful tool that not only helps farmers make mating decisions that fit their individual needs and farming objectives but also highlights the vital role that reproductive performance plays in the rate of genetic gain and on-farm productivity.

\section{CONCLUSIONS}

Given the importance of genetic gain in the profitability of New Zealand dairy farming, there is a widespread desire to continually improve herd genetics. Breeding companies are producing the most genetically superior bulls possible, and many farmers strive to maximize the rate of genetic gain in their herds. Optimal strategies for improving $\mathrm{BrW}$ will vary from farm to farm depending not only on the BrW structure of the herd and the bull team available but also on farm management practices and breeding objectives. Traditionally, it has been a widespread belief that genetic gain would be maximized by nominating top cows to only the very top bulls. However, results here show only small improvements in $\mathrm{BrW}$ of replacement heifers when such strategies are used. The results from the simulations undertaken in this study demonstrate that excluding cows with the lowest $\mathrm{BrW}$ from producing replacement heifers is most effective for improving $\mathrm{BrW}$ regardless of herd or bull team structure. However, when using these strategies, care must be taken to ensure that sufficient heifer calves are generated. 


\section{ACKNOWLEDGMENTS}

We acknowledge Vivienne Bennett for critical reading of the manuscript.

\section{REFERENCES}

Börner, V., F. Teuscher, and N. Reinsch. 2012. Optimum multistage genomic selection in dairy cattle. J. Dairy Sci. 95:2097-2107.

Calus, M. P., P. Bijma, and R. F. Veerkamp. 2015. Evaluation of genomic selection for replacement strategies using selection index theory. J. Dairy Sci. 98:6499-6509.

Cropp, R. 2003. The supply and demand of dairy heifer replacements. Accessed Apr. 4, 2017. http://future.aae.wisc.edu/publications/s _d_heifer_replacements.pdf.

Dairy NZ. 2014a. All about BW. Accessed Apr. 7, 2017. https://www .dairynz.co.nz/animal/animal-evaluation/interpreting-the-info/all -about-bw/.

Dairy NZ. 2014b. QuickStats about dairying-New Zealand. Accessed Apr. 4, 2017. https://www.dairynz.co.nz/media/1357994/ quickstats-new-zealand.pdf.

Dairy NZ. 2015. BW explained. Accessed Nov. 10, 2017. https://www .dairynz.co.nz/media/2886712/BW_Explained_Oct_2015.pdf.

Dairy NZ. 2017. Ranking of active sires list. Accessed Mar. 29, 2017. https://www.dairynz.co.nz/animal/animal-evaluation/ranking-of -active-sires-ras/.

Ettema, J. F., J. R. Thomasen, L. Horto, M. Kargo, S. Ostergaard, and A. C. Sorensen. 2017. Economic opportunities for using sexed semen and semen in beef bulls in dairy herds. J. Dairy Sci. 100:4161-4171.

Harris, B., J. E. Pryce, and W. A. Montgomerie. 2007. Experiences from breeding for economic efficiency in dairy cattle in New Zealand. Proc. Assoc. Advance. Anim. Breed. Genet. 17:434-444.
Holmes, C., I. Brookes, J. Roche, J. Simmonds, E. Kolver, J. Kleinmans, S. Ledgard, M. Robinson, C. Pyke, I. Williams, D. Miller, S. Beynon, B. Montgomery, T. Fraser, J. Deutz-Ebeling, M. Blackwell, J. White, J. McPherson, S. Lee, C. Glassey, E. Thom, V. Serra, M. Hunter, B. Schouten, P. Irvine, W. Berry, K. Reid, L. Hendrikse, C. Finnigan, D. Dalley, J. Lacy-Hulbert, A. Fergusson, H. Lawson, C. Burke, R. Brazendale, P. Hedley, and A. Lambourne. 2010. Facts and figures for New Zealand dairy farmers. Accessed May 17, 2017. https://www.dairynz.co.nz/media/2816711/facts -and-figures-dairynz.pdf.

Holmes, C. W., I. M. Brookes, D. J. Garrick, D. D. S. MacKenzie, T. J. Parkinson, and G. F. Wilson. 2002. Mating and fertility in the herd. Pages 159-174 in Milk Production from Pasture: Principles and Practices. D. Swain, ed. Massey University, Palmerston North, New Zealand.

LIC (Livestock Improvement Corporation) and DairyNZ. 2016. New Zealand Dairy Statistics 2015-16. LIC and Dairy NZ, Hamilton, New Zealand.

Pryce, J. E., B. L. Harrie, S. Sim, and A. W. McPherson. 2006. Genetics of stillbirth in dairy calves. Proc. N.Z. Soc. Anim. Prod. 66:98-102.

R Core Team. 2014. R: A Language and Environment for Statistical Computing. R Foundation for Statistical Computing, Vienna, Austria.

Reiner-Benaim, A., E. Ezra, and J. I. Weller. 2017. Optimization of a genomic breeding program for a moderately sized dairy cattle population. J. Dairy Sci. 100:2892-2904.

Thomasen, J. R., A. Willam, C. Egger-Danner, and A. C. Sorensen. 2016. Reproductive technologies combine well with genomic selection in dairy breeding programs. J. Dairy Sci. 99:1331-1340. 